Original Article

\title{
Effects of mechanical horseback riding velocity on spinal alignment in young adults
}

\author{
Jae-Heon Lim, PT, PhD ${ }^{1)}$, Woon-Su Cho, PT, PhD ${ }^{2)}$, Seong-Jin Lee, PhD ${ }^{3)}$, \\ Chi-Bok Park, PT, $\mathrm{MSc}^{4}$, JAng-Sung PArk, PT, $\mathrm{PhD}^{1)^{*}}$ \\ 1) Department of Physical Therapy, Seonam University: 439 Chunnhyang-ro, Namwon-si, Jellabuk-do \\ 55724, Republic of Korea \\ 2) Department of Physical Therapy, Nambu University, Republic of Korea \\ 3) Department of Rehabilitation Health Management, Songwon University, Republic of Korea \\ 4) Department of Physical Therapy, Graduate School of Dongshin University, Republic of Korea
}

\begin{abstract}
Purpose] This study aimed to determine if the velocity of mechanical horseback-riding training can improve spinal alignment in young adults. [Subjects and Methods] Thirty-six subjects were enrolled in this study. The subjects were randomly allocated into high-, moderate-, and low-velocity mechanical horseback-riding training groups. All participants completed one 20-minute session per day, 3 days per week, for 6 weeks. The evaluation was performed before and 6 weeks after the training intervention. The spinal alignment was measured by a Formetric III device. The measurement items were kyphotic angle, lordotic angle, trunk inclination, pelvic torsion, pelvic rotation, and lateral deviation. The data were analyzed using analysis of covariance to determine the statistical significance. [Results] The kyphotic angle and trunk inclination were significantly different among the groups. The kyphotic angles of the high- and moderate-velocity groups were significantly lower than that of the low-velocity group after the intervention. The trunk inclination of the high-velocity group was significantly lower than that of the low-velocity group after intervention. [Conclusion] Higher-velocity mechanical horseback-riding training is more effective than lower-velocity mechanical horseback-riding training for improving spinal alignment.

Key words: Horseback-riding, Horseback-riding velocity, Spinal alignment
\end{abstract}

(This article was submitted Jan. 25, 2016, and was accepted Mar. 12, 2016)

\section{INTRODUCTION}

Horseback riding has been used in children with intellectual disability, stroke, and cerebral palsy and has been applied widely as a rehabilitation approach for individuals of all ages with disabilities ${ }^{1}$. A horse's movements are rhythmic and repetitive and appear to be similar to the human gait ${ }^{2}$. In particular, horseback riding can have walking-related treatment effects due to its emulation of human pelvis movements while walking ${ }^{3)}$. Depending on the horse's movement, the rider experiences a wide range of motion of 500 to 1,000 times over a 10-minute period. Such movements help improve the rider's posture, muscle strength, balance, and coordination ${ }^{4)}$.

Although rehabilitation using horses has many benefits, problems such as high economic cost and labor shortages due to insufficient infrastructure and a lack of rehabilitation horseback-riding therapists persist. Therefore, its implementation is difficult ${ }^{5}$ ). In addition, the largest problem of horse-based rehabilitation is the potential accidents caused by falling, for which there is no practical prevention ${ }^{6}$. To overcome these problems, attempts have been made to use a machine to mimic a horse's movements. Horseback riding using machines and appliances for horseback riding therapy appears to have similar effectiveness in rehabilitation ${ }^{7,8}$. The reported mechanical horseback-riding training (MHRT) has physical effects similar to the movement trajectory of an actual horse ${ }^{9)}$.

*Corresponding author. Jang-Sung Park (E-mail: sensory7@hanmail.net)

(C2016 The Society of Physical Therapy Science. Published by IPEC Inc.

This is an open-access article distributed under the terms of the Creative Commons Attribution Non-Commercial No Derivatives (by-nc-nd) License $<$ http://creativecommons.org/licenses/by-nc-nd/4.0/>. 
Thus far, horseback-riding training with machines has focused on children with cerebral palsy ${ }^{10)}$ and stroke patients ${ }^{11)}$, elderly people ${ }^{12}$ ) and research to verify the effects of exercise have been reported. Although MHRT effectively improves muscle strength, posture, and symmetry $\left.{ }^{13}, 14\right)$, little research has investigated velocity-based differences. Therefore, this study examined the differences specific to MHRT velocity on spinal alignment to determine whether MHRT can be considered as a therapeutic intervention.

\section{SUBJECTS AND METHODS}

Thirty-six young adults participated in this study. The adults were recruited from S university in Namwon, Korea and were randomly allocated to the high-velocity MHRT (HV-HRST; n=12), moderate-velocity MHRT (MV-HRST; n=12), and lowvelocity MHRT (LV-HRST; $\mathrm{n}=12$ ) groups. The subjects in all groups performed 18 sessions ( 3 times a day for 20 minutes each day for 6 weeks). All subjects read and signed informed consent forms in accordance with the ethical standards of the Declaration of Helsinki.

The horseback-riding equipment (FORTIS 101, Daewon, Korea) was similar in size (width, $580 \mathrm{~mm}$; length, $1900 \mathrm{~mm}$ ), height $(1,700 \mathrm{~mm})$, and weight $(315 \mathrm{~kg})$ to an actual horse. The experiment was performed using $71-80$ of 100 courses in the main exercise area for the neck, shoulders, torso, abdomen, waist, hips, and thighs. Each course was applied for 2 minutes; a total of 10 courses were performed over 20 minutes. The participants were wearing an automatic stop device to prevent falls. If the participants were afraid of falling, safety bars were placed on either side. If they were not anxious, the reins were taken. The first time they climbed into the saddle riding, they were encouraged to use a wooden staircase to relieve any psychological anxiety. In addition, a full description was given to help the participants understand the MHRT. Table 1 summarizes the subjects' demographic data.

The groups were separated by rate: $85-90$ cycle/min (high speed), 55-60 cycle/min (moderate speed), and 25-30 cycle/ min (low speed). Rider momentum differed significantly from that of actual horseback riding ${ }^{15}$. The Formetric III was used to analyze spinal alignment in three dimensions. The Formetric III can automatically detect certain areas of the body for imaging, such as a subject's back, without the need for manually attached anatomical markers. In addition, there is no exposure to radiation, such as X-rays, because spinal deformations can be measured quickly using a halogen lamp, a white light system. DICAM basic software was used for the analysis. The length and width of the space was $3.0,3.5 \mathrm{~m}$, and $1.5 \mathrm{~m}$, respectively, and the time was $0.04-60$ seconds. The results obtained with the equipment were compared with the radiation measurements, and high accuracy and reliability was observed ${ }^{16}$. The parameters measured were the kyphotic angle, lordotic angle, trunk inclination, pelvic torsion, pelvic rotation, and lateral deviation.

This study used SPSS for MAC (21.0 version). All measurements are reported as the mean \pm standard deviation. One-way analysis of variance (ANOVA) was used to compare the general characteristics of the subjects, such as age, height, and weight among the three groups. A comparison with all groups in spinal alignment was analyzed by ANCOVA. The pre-test values of each group were used as covariates for adjustment. A post-hoc multiple comparison was performed using the least significant difference (LSD). The statistical significance level was set to $\alpha=0.05$.

\section{RESULTS}

Among the dependent variables of spinal alignment, the lordotic angle, pelvic torsion, pelvic rotation, lateral deviation were similar in the groups after the intervention $(\mathrm{p}>0.05)$. The kyphotic angle a trunk inclination after the intervention were significantly different between the groups $(\mathrm{p}<0.05)$ (Table 2). The post-hoc test showed that the kyphotic angle of the LVMHRT group was significantly different compared to that of the MV-MHRT and HV-MHRT groups. The trunk inclination of the HV-MHRT group was significantly different from the LV-MHRT $(\mathrm{p}<0.05)$.

\section{DISCUSSION}

The strength of horseback-riding is determined by the speed of the moving horse ${ }^{17)}$. Horseback-riding shows real changes in the walking step and in the movement of the horse, depending on horse's velocity, which can lead to changes in the rider's movement. Reacting to the rider's center of gravity according to the horse's movement can have an effect on the posture

Table 1. General subject characteristics

\begin{tabular}{lccc}
\hline Characteristics & HV-MHRT & MV-MHRT & LV-MHRT \\
\hline Age (years) & $23.9 \pm 1.2$ & $23.9 \pm 1.2$ & $24.5 \pm 1.3$ \\
Height $(\mathrm{cm})$ & $168 \pm 8$ & $168 \pm 8.1$ & $168.5 \pm 8.6$ \\
Weight $(\mathrm{kg})$ & $58.7 \pm 9.8$ & $63.7 \pm 11.8$ & $63.1 \pm 14.3$ \\
\hline HV-MHRT: high-velocity mechanical horseback-riding training; MV-MHRT: & moderate-velocity \\
MHRT; LV-MHRT: low-velocity MHRT
\end{tabular}


alignment and can reorganize the rider's balance strategy ${ }^{18)}$. If the rider responds to changes in the speed of a horse in a sitting position, the feedforward of the unexpected movement of the horse and feedback will appear, which determines the postural adjustment needed to perform the selected task. As the speed of horse riding increases, the actual type of horse walking and the movement of horse riding also appears to be different. The aim of this study was to determine if MHRT depending on velocity could affect the spinal alignment in young adults by using Formetric III device.

The results showed a significant difference in trunk inclination and kyphotic angle among the groups. The post-hoc results showed that the kyphotic angle of the HV-MHRT and MV-MHRT groups was significantly lower than that of the LV-MHRT group. The trunk inclination of the HV-MHRT group was significantly lower than that of the LV-MHRT group. The more reduced the trunk inclination, the greater the increase in trunk extension. That is, the angle is reduced from tipping forward in the sagittal plane. The HV-MHRT group would see the trunk extension as helpful. In a study that investigated the kinematic changes in the rider's movement during riding, the high speed of horseback-riding was maintained $2.46 \mathrm{~cm}$ larger than the width in the vertical direction of normal speed riding ${ }^{19}$. In addition, the elbow joint was more flexed from moving at high speed, and the shoulder joint was more in extension. The shoulder joint due to extension can be viewed as making a greater contribution to the extension of the thoracic area.

The results of a study of the effects of horseback-riding on trunk posture in mentally retarded children revealed a decrease in trunk inclination after 16 weeks of horseback-riding, indicating a beneficial effect on the trunk posture correction ${ }^{20)}$. The decreased kyphosis was attributed to thoracic extensor strengthening. The results of the back muscle cross-sectional area of patients with scoliosis, who underwent mechanical movement, showed an increase in the right and left back muscle area from $4.87 \mathrm{~cm}^{2}$ to $5.50 \mathrm{~cm}^{2}$, and from $4.43 \mathrm{~cm}^{2}$ to $4.83 \mathrm{~cm}^{2}$, respectively.

The MVIC of the back muscles also increased from $3.73 \mathrm{~kg}$ to $6.70 \mathrm{~kg}^{13}$. In a study comparing the effectiveness of Kendall exercise and MHRT on the forward head posture suggested that MHRT more effective than Kendall exercise ${ }^{21)}$. The forward head posture is primarily a forward posture of the neck that naturally increases when the kyphosis is increased by round shoulders and scapular protraction. Therefore, the results of the present study shows some agreement with that study in that it helps to improve the forward head posture.

In contrast, MHRT had no significant effect on posture in 9 frail elderly people, and there was no significant difference in the thoracic kyphosis angle ${ }^{22}$. During the 12 week period, individuals with limited functional physical activity in the horseback-riding group showed a gradual increase in speed, particularly at 1, 4, and 8 weeks. In the present study, subjects were consistently at the fastest speed in HV-MHRT over the 6-week period, while each subject was at the speed and rate at which the seniors could adapt. In addition, the fastest MHRT movement speed was a rate 3.6 times per second; the slowest was proceeded at a rate of 1.7 times per second. The velocity difference showed different results.

Although kyphosis was significantly different, the lordosis angle in the HV-MHRT group showed no significant differences. This is because the HV-MHRT group is a fixed set of both legs through the pelvis to the static contractions of the pelvic muscle contraction and the action to extend both arms holding the reins occurred more strongly. The lateral deviation, pelvic torsion, and pelvic rotation did not show a significant difference. In particular, the lateral deviation was significantly more effective in the LV-MHRT. The lateral deviation means symmetry close to zero. Because LV-MHRT showed a lower value than the HV-MHRT and MV-MHRT group, the left and right body symmetry was effective in low velocity.

Although the HV-MHRT group had more power in the hands on the reins than in both legs and pelvis because reactive posture control moves at a faster speed, the LV-MHRT helped balance the body with relatively anticipatory postural adjustments

Table 2. Comparison of spinal alignment among the treatment groups

\begin{tabular}{llccc}
\hline Variable & & HV-MHRT & MV-MHRT & LV-MHRT \\
\hline \multirow{2}{*}{ Kyphotic angle (deg) } & pre & $41.42 \pm 6.24$ & $43.76 \pm 10.74$ & $44.21 \pm 5.98$ \\
& post & $40.89 \pm 4.49$ & $43.00 \pm 9.31$ & $49.22 \pm 6.23^{\dagger}$ \\
Lordotic angle (deg) & pre & $31.01 \pm 8.06$ & $40.27 \pm 11.65$ & $37.47 \pm 9.33$ \\
& post & $31.83 \pm 7.51$ & $40.31 \pm 9.96$ & $35.67 \pm 8.93$ \\
Trunk inclination (deg) & pre & $2.18 \pm 1.04$ & $1.77 \pm 1.61$ & $1.88 \pm 1.19$ \\
& post & $1.52 \pm 1.29$ & $2.21 \pm 1.19$ & $2.70 \pm 1.67^{\dagger}$ \\
Pelvic torsion (deg) & pre & $1.60 \pm 1.21$ & $2.41 \pm 1.52$ & $2.53 \pm 1.68$ \\
& post & $2.22 \pm 1.33$ & $2.81 \pm 1.99$ & $2.03 \pm 1.18$ \\
Pelvic rotation (deg) & pre & $3.61 \pm 2.35$ & $3.91 \pm 3.27$ & $2.02 \pm 1.15$ \\
& post & $3.08 \pm 2.46$ & $3.59 \pm 2.54$ & $2.39 \pm 1.63$ \\
Lateral deviation (deg) & pre & $5.01 \pm 3.07$ & $4.13 \pm 1.82$ & $4.58 \pm 1.84$ \\
& post & $5.15 \pm 2.32$ & $4.97 \pm 1.92$ & $3.37 \pm 1.55$ \\
\hline
\end{tabular}

Values are reported as the mean \pm standard deviation; HV-MHRT: high-velocity mechanical horseback-riding training; MV-MHRT: moderate-velocity MHRT; LV-MHRT: low-velocity MHRT; †significant difference between HV-MHRT and LV-MHRT, *significant difference between MV-MHRT and LV-MHRT. 
in response to the movement of the moving saddle, which is expected to contribute more to the symmetry of the body ${ }^{14)}$.

This study has some limitations. The physical ability of the individual was not considered as including it was difficult because of the small sample size. In addition, one-handed and both handed subjects were not selected considering the dominant hand because it affects the reporting spinal symmetry. Future research will compare the difference according to the horseback-riding speed targeting people with scoliosis or deficiencies in spinal alignment.

\section{REFERENCES}

1) Tseng SH, Chen HC, Tam KW: Systematic review and meta-analysis of the effect of equine assisted activities and therapies on gross motor outcome in children with cerebral palsy. Disabil Rehabil, 2013, 35: 89-99. [Medline] [CrossRef]

2) MacPhail HA, Edwards J, Golding J, et al.: Trunk postural reactions in children with and without cerebral palsy during therapeutic horseback riding. Pediatr Phys Ther, 1998, 10: 143-147. [CrossRef]

3) Potter JT, Evans JW, Nolt BH Jr: Therapeutic horseback riding. J Am Vet Med Assoc, 1994, 204: 131-133. [Medline]

4) Benda W, McGibbon NH, Grant KL: Improvements in muscle symmetry in children with cerebral palsy after equine-assisted therapy (hippotherapy). J Altern Complement Med, 2003, 9: 817-825. [Medline] [CrossRef]

5) Hosaka Y, Nagasaki M, Bajotto G, et al.: Effects of daily mechanical horseback riding on insulin sensitivity and resting metabolism in middle-aged type 2 diabetes mellitus patients. Nagoya J Med Sci, 2010, 72: 129-137. [Medline]

6) Siebenga J, Segers MJ, Elzinga MJ, et al.: Spine fractures caused by horse riding. Eur Spine J, 2006, 15: 465-471. [Medline] [CrossRef]

7) Herrero P, Gómez-Trullén EM, Asensio A, et al.: Study of the therapeutic effects of a hippotherapy simulator in children with cerebral palsy: a stratified singleblind randomized controlled trial. Clin Rehabil, 2012, 26: 1105-1113. [Medline] [CrossRef]

8) Araujo TB, Silva NA, Costa JN, et al.: Effect of equine-assisted therapy on the postural balance of the elderly. Rev Bras Fisioter, 2011, 15: 414-419. [Medline] [CrossRef]

9) Shinomiya Y, Wang S, Ishida K, et al.: Development and muscle strength training evaluation for horseback riding therapeutic equipment. J Rob Mechatron, 2002, 14: 597-603.

10) Lee CW, Kim SG, Na SS: The effects of hippotherapy and a horse riding simulator on the balance of children with cerebral palsy. J Phys Ther Sci, 2014, 26: 423-425. [Medline] [CrossRef]

11) Baek IH, Kim BJ: The effects of horse riding simulation training on stroke patients' balance ability and abdominal muscle thickness changes. J Phys Ther Sci, 2014, 26: 1293-1296. [Medline] [CrossRef]

12) Cho SH, Kim JW, Kim SR, et al.: Effects of horseback riding exercise therapy on hormone levels in elderly persons. J Phys Ther Sci, 2015, 27: 2271-2273. [Medline] [CrossRef]

13) Lee DR, Lee NG, Cha HJ, et al.: The effect of robo-horseback riding therapy on spinal alignment and associated muscle size in MRI for a child with neuromuscular scoliosis: an experimenter-blind study. NeuroRehabilitation, 2011, 29: 23-27. [Medline]

14) McGibbon NH, Benda W, Duncan BR, et al.: Immediate and long-term effects of hippotherapy on symmetry of adductor muscle activity and functional ability in children with spastic cerebral palsy. Arch Phys Med Rehabil, 2009, 90: 966-974. [Medline] [CrossRef]

15) Nankervis K, Lovett T, Hodson-Tole E, et al.: A preliminary investigation of rider position during walk, trot and canter. Equine Comp Exerc Physiol, 2005, 2 : 71-76. [CrossRef]

16) Hackenberg L, Hierholzer E, Pötzl W, et al.: Rasterstereographic back shape analysis in idiopathic scoliosis after anterior correction and fusion. Clin Biomech (Bristol, Avon), 2003, 18: 1-8. [Medline] [CrossRef]

17) Quint C, Toomey M: Powered saddle and pelvic mobility: an investigation into the effects on pelvic mobility of children with cerebral palsy of a powered saddle which imitates the movements of a walking horse. Physiotherapy, 1998, 84: 376-384. [CrossRef]

18) Shumway-Cook A, Woollacott MH: Motor control: translating research into clinical practice, 3rd ed. Philadelphia: Lippincott Williams \& Wilkins, 2007, pp $160-163$.

19) Oh WY, Ryew CC, Kim JH, et al.: Kinematic analysis of horse-riding posture during walking and rising trot in Jeju horse. J Sport Leis Stud, 2009, 38: 741-754.

20) Lim SG, Han SH: The effects of horse riding on posture and figure in children with mental retardation. Journal of Special Physical Education, Yongin University, 2004, 2: 97-106.

21) Kim KH, Kim SG, Hwangbo G: The effects of horse-riding simulator exercise and Kendall exercise on the forward head posture. J Phys Ther Sci, 2015, 27: 1125-1127. [Medline] [CrossRef]

22) Mitani Y, Doi K, Yano T, et al.: Effect of exercise using a horse-riding simulator on physical ability of frail seniors. J Phys Ther Sci, 2008, 20: 177-183. [CrossRef] 